\title{
Gigantic Peripheral Osteoma of the Mandible: A Case Report
}

\author{
Göksel Şimşek Kaya ${ }^{1}$, Mehmet Melih Ömezli ${ }^{2}$, Sare Şipal ${ }^{3}$, Ümit Ertaş ${ }^{4}$ \\ ${ }^{1}$ Assistant Professor, Department of Oral and Maxillofacial Surgery, Faculty of Dentistry, Atatürk University. \\ ${ }^{2}$ Research Assistant, Department of Oral and Maxillofacial Surgery, Faculty of Dentistry, Atatürk University. \\ ${ }^{3}$ Assistant Professor, Department of Pathology, Faculty of Medicine, Atatürk University. \\ ${ }^{4}$ Professor, Department of Oral and Maxillofacial Surgery, Faculty of Dentistry, Atatürk University.
}

Correspondence:

Dr. Göksel Șimșek Kaya

Atatürk University,

25240 Erzurum (Turkey)

E-mail address: gokselsimsek@yahoo.com

Kaya GŞ, Ömezli MM, Şipal S, Ertaș Ü. Oral myiasis: Gigantic Peripheral Osteoma of the Mandible: A Case Report. J Clin Exp Dent. 2010;2(3):e160-2.

http://www.medicinaoral.com/odo/volumenes/v2i3/jcedv2i3p160.pdf

$$
\begin{aligned}
& \text { Article Number: } 50343 \quad \text { http://www.medicinaoral.com/odo/indice.htm } \\
& \text { (C) Medicina Oral S. L. C.I.F. B } 96689336 \text { - eISSN: 1989-5488 }
\end{aligned}
$$$$
\text { eMail: jced@jced.es }
$$

\begin{abstract}
Osteomas are osteogenic lesions that have a limited growth potential. They are comprised of histologically and radiographically normal bone. Osteomas are categorized as central, peripheral or extraskeletal according to location. Clinically, peripheral osteomas (PO) are unilateral, sessile or pedunculated and have mushroom-like lesions ranging from 10 to $40 \mathrm{~mm}$ in diameter. Osteomas affecting the mandible are rare. In this report, we presented a gigantic peripheral mass on the left mandible in a 55-year old patient exhibiting clinical signs related to neoplasia.
\end{abstract}

Key words: Peripheral osteoma, mandible, surgery. 


\section{Introduction}

Osteoma is a bone lesion characterized by proliferation of compact, cancellous mature bone cells or both (1-3). It is debatable whether osteomas are a benign neoplasm or a hamartoma type lesion (1). In general, osteomas grow slowly and progressively (1-3) and are categorized as central, peripheral or extraskeletal according to location (1-5). Clinically, peripheral osteomas (PO) are unilateral, sessile or pedunculated and have mushroomlike lesions ranging from 10 to $40 \mathrm{~mm}$ in diameter (2-4). They appear radiographically as well-circumscribed radiopaque masses that appear round or ovoid in shape $(1,2,4)$. Osteomas affecting the mandible are rare (1-3). Few cases reported in the literature reached the size of the presented case $(2,3)$. In this report, we presented a gigantic PO invading the lingual part of the left mandibular corpus.

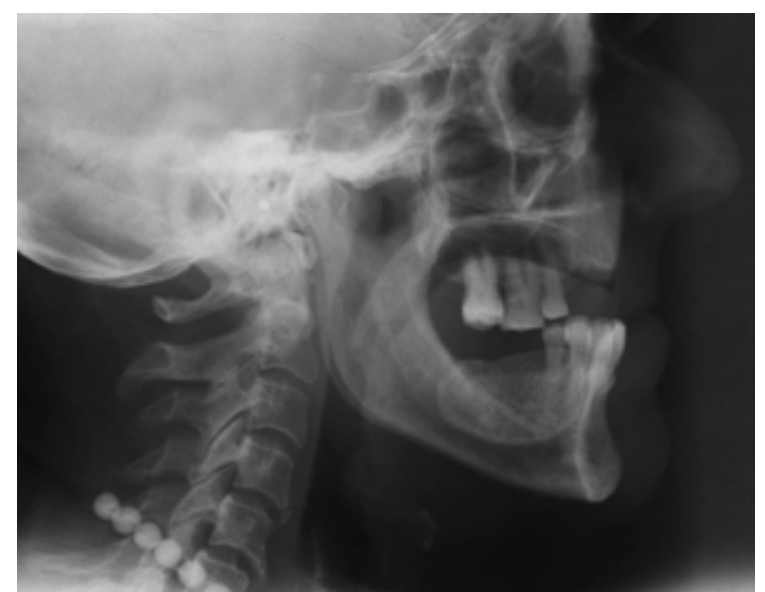

Fig.1. Lateral skull radiography of the lesion on the left mandible.

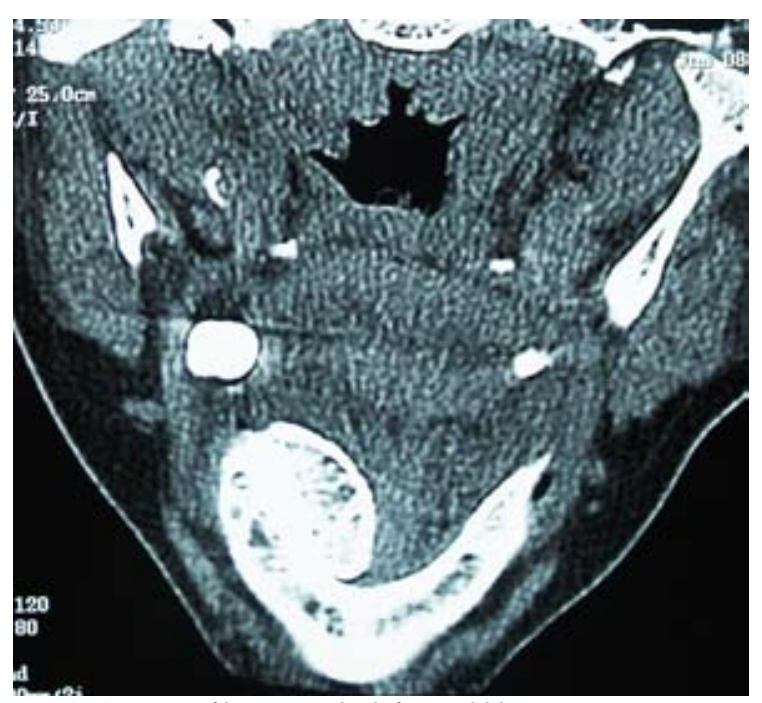

Fig. 2. CT scan of lesion on the left mandible.

\section{Case Report}

A 55-year-old female patient was referred to our oral and maxillofacial surgery services on June 01, 2008 for preprosthetic surgical evaluation of a slowly grown asymptomatic mass that extended from the left lower central incisor to mandibular ramus in the lingual part of the left mandible. Because of the size of the lesion, the patient complained about of functional impairment. Upon intraoral examination, there was an immobile, hard and well-circumscribed mass that diffused to the lingual part of the left mandible. This subperiostal mass was covered with normal mucosa. Lateral skull radiography and computed tomography, however, revealed a well-circumscribed and sessile mass with a dense radiopaque area (Figs. 1 and 2). The patient reported neither a previous systemic illness nor traumatic exposure. However, she was unable to confirm the duration of the lesion's presence. Vitality tests for all teeth in the lower mandible were positive, and regional lymph nodules were in normal dimension. Laboratory measures were within physiological limits. There were no signs related to Gardner's syndrome.

A full-thickness subperiostal flap was reflected intraorally via circular incision under local anesthesia. An excisional biopsy was performed using rotary instruments and a bone chisel. The cortical bone of the mandible was shaped and smoothed before closing the flap (Fig. 3). A microscopic evaluation of the specimen showed no

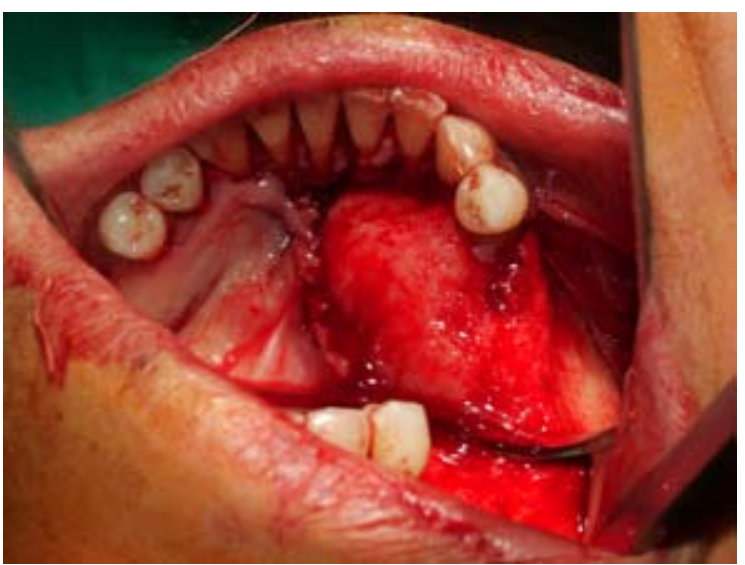

Fig. 3. Intra-operative view of the lesion.

signs of inflammation, but loose stroma among intensive lamellous bone structures were evident (Fig. 4). Our patient is under control periodically for the risk of recurrence.

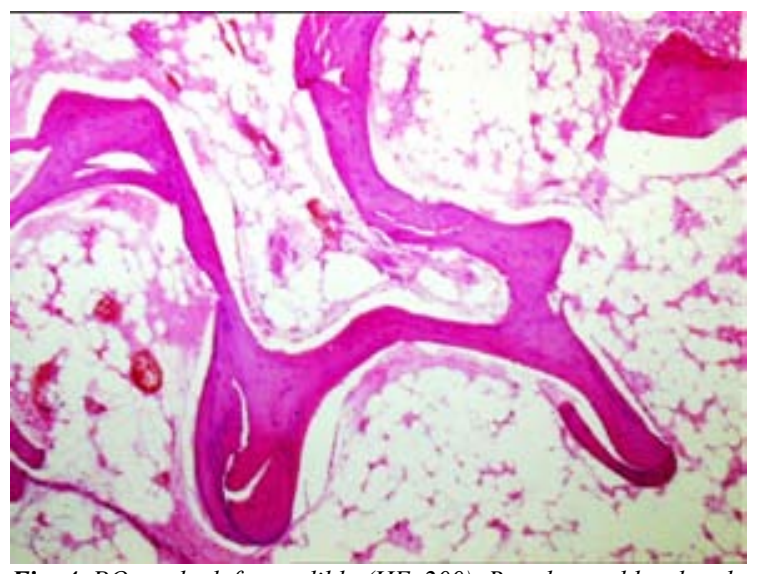

Fig. 4. PO on the left mandible (HEx200). Regular and bordered mature bone tissue. 


\section{Discussion}

Because it often develops without sign or symptoms other than expansion, patients with PO visit the dentist. Surgical intervention is indicated when the tumor is symptomatic, interferes cosmetically or functionally or is actively growing $(2,3)$. Surgical intervention varies according to the dimension and localization of the mass $(1,3)$.

Histologically, presence of other neoplastic or inflammatory lesions such as exostoses, ossifying fibroma, chronic focal sclerose osteomyelitis, fibrous dysplasia, Paget's disease, chondroma, osteosarcoma should be excluded prior to the diagnosis of osteomas that are associated with various osteoblastic and osteoclastic activities $(1,2,4)$. Gardner's syndrome defined as multiple osteomas of the jaws accompanied by colorectal polyps with high malignity, anomalies involving soft or hard tissues, congenital retinal pigment hypertrophies, and multiple impacted or supernumerary teeth, enostoses, or epidermoid cysts $(2,4)$. Johann et al. (4) reported 63 mandibular PO cases unrelated to Gardner's syndrome in literature published in English between 1927 and 2003. Since osteoma in autosomal dominant Gardner's syndrome generally develops before colorectal polyps, early diagnosis can be import for saving life $(2,3)$. Our patient did not present any sign of this syndrome.

Despite their known clinical, radiographic and histological characteristics, the pathogenesis of osteomas is largely unknown. According to researchers favoring the reactive theory, such minimal trauma can cause edema, hemorrhage, and muscle traction, which consequently results in increased regional osteogenic activity. Moreover, they postulate that osteoma generally develops in regions that are prone to trauma, such as the angle, lower border, or buccal aspect of the mandible and buccal aspect of the maxilla, as well as attachment areas of the masticator muscles (1-3). However, development of osteoma in other locations may suggest involvement of other factors in addition to predisposition $(1,4)$.

Varboncoeur et al. (5) have postulated that osteomas originate from embryological cartilaginous rests or persistent embryological periosteum. Since this tumor occurs in the adults, many author refute this postulation $(1,2)$. It is not possible to deny the embryological theory here because our patient could not recall or confirm traumatic exposure and onset of lesion development.

Some researchers claim that osteomas are not neoplastic, based on evidence that this tumor has a limited growth potential, malignant transformation potential and rare recurrence $(2,3)$. However, the gigantic mass's progressive but slow growth and the patient's lack of previous exposure to trauma in the present case may refute this claim.

\section{Conclusion}

PO can infrequently develop and reach large dimensions as did in the present case. Histopathological examination of lesions is required for an absolute diagnosis and malignity especially in gigantic osteomas should be considered despite typical clinical and radiographical signs.

\section{References}

1. Dalambiras S, Boutsioukis C, Tilaveridis I. Peripheral osteoma of the maxilla: report of an unusual case. Oral Surg Oral Med Oral Pathol Oral Radiol Endod. 2005;100:19-24.

2. Iatrou IA, Leventis MD, Dais PE, Tosios KI. Peripheral osteoma of the maxillary alveolar process. J Craniofac Surg. 2007;18:1169-73.

3. Woldenberg Y, Nash M, Bodner L. Peripheral osteoma of the maxillofacial region. Diagnosis and management: a study of 14 cases. Med Oral Patol Oral Cir Bucal. 2005;10 suppl 2:139-42.

4. Johann AC, de Freitas JB, De Aguiar MC, De Araújo NS, Mesquita RA. Peripheral osteoma of the mandible: case report and review of the literature. J Craniomaxillofac Surg. 2005;33:276-81.

5. Varboncoeur AP, Vanbelois HJ, Bowen LL. Osteoma of the maxillary sinus. J Oral Maxillofac Surg. 1990;48: 882-3. 